\title{
Multigene Panel Germline Testing of 1333 Czech Patients with Ovarian Cancer
}

\author{
Klara Lhotova ${ }^{1,2}$, Lenka Stolarova ${ }^{1}$, Petra Zemankova ${ }^{1,2}$, Michal Vocka ${ }^{3}$, , Marketa Janatova ${ }^{1,2}$, \\ Marianna Borecka 1,2 ${ }^{1 D}$, Marta Cerna ${ }^{1}$, Sandra Jelinkova ${ }^{1}$, Jan Kral ${ }^{1}$, Zuzana Volkova ${ }^{1}$, \\ Marketa Urbanova ${ }^{2}$, Petra Kleiblova ${ }^{2}$ D, Eva Machackova ${ }^{4}$, Lenka Foretova ${ }^{4}$, Jana Hazova ${ }^{4}$, \\ Petra Vasickova ${ }^{4}$, Filip Lhota ${ }^{5}$, Monika Koudova ${ }^{5}\left(\mathbb{D}\right.$, Leona Cerna ${ }^{5}$, Spiros Tavandzis ${ }^{6}(\mathbb{D})$, \\ Jana Indrakova ${ }^{6}$, Lucie Hruskova ${ }^{7}$, Marcela Kosarova ${ }^{8}$, Radek Vrtel ${ }^{9}$, Viktor Stranecky ${ }^{10}$, \\ Stanislav Kmoch ${ }^{10}$, Michal Zikan ${ }^{11}$, Libor Macurek ${ }^{12}{ }^{\mathbb{D}}$, Zdenek Kleibl ${ }^{1}$ (D) and \\ Jana Soukupova $1,2, *$ D
}

1 Institute of Biochemistry and Experimental Oncology, First Faculty of Medicine, Charles University, 12853 Prague, Czech Republic; Klara.Lhotova@lf1.cuni.cz (K.L.); lenka.stolarova@lf1.cuni.cz (L.S.); petra.boudova@lf1.cuni.cz (P.Z.); mjana@lf1.cuni.cz (M.J.); boreckam@gmail.com (M.B.); marta.cerna@lf1.cuni.cz (M.C.); sandra.jelinkova@lf1.cuni.cz (S.J.); jan.kral@lf1.cuni.cz (J.K.); zuzana.klusonova@lf1.cuni.cz (Z.V.); zdekleje@lf1.cuni.cz (Z.K.)

2 Institute of Biology and Medical Genetics, First Faculty of Medicine, Charles University and General University Hospital in Prague, 12800 Prague, Czech Republic; Marketa.Urbanova@vfn.cz (M.U.); pekleje@lf1.cuni.cz (P.K.)

3 Department of Oncology, First Faculty of Medicine, Charles University and General University Hospital in Prague, 12808 Prague, Czech Republic; Michal.Vocka@vfn.cz

4 Department of Cancer Epidemiology and Genetics, Masaryk Memorial Cancer Institute, 65653 Brno, Czech Republic; emachack@mou.cz (E.M.); foretova@mou.cz (L.F.); hazova@mou.cz (J.H.); vasickova@mou.cz (P.V.)

5 Department of Medical Genetics, Centre for Medical Genetics and Reproductive Medicine, Gennet, 17000 Prague, Czech Republic; Filip.Lhota@gennet.cz (F.L.); Monika.Koudova@gennet.cz (M.K.); Leona.Cerna@gennet.cz (L.C.)

6 Department of Medical Genetics, AGEL Laboratories, AGEL Research and Training Institute, 74101 Novy Jicin, Czech Republic; spiros.tavandzis@lab.agel.cz (S.T.); jana.indrakova@lab.agel.cz (J.I.)

7 Department of Medical Genetics, GHC Genetics, 11000 Prague, Czech Republic; hruskova@ghc.cz

8 Department of Medical Genetics, Pronatal, 14700 Prague, Czech Republic; kosarova@pronatal.cz

9 Department of Medical Genetics, University Hospital Olomouc, Faculty of Medicine and Dentistry, Palacky University Olomouc, 77900 Olomouc, Czech Republic; radek.vrtel@fnol.cz

10 Research Unit for Rare Diseases, Department of Pediatrics and Adolescent Medicine, First Faculty of Medicine, Charles University and General University Hospital in Prague, 12808 Prague, Czech Republic; vstra@lf1.cuni.cz (V.S.); skmoch@lf1.cuni.cz (S.K.)

11 Department of Gynecology and Obstetrics, Hospital Na Bulovce and First Faculty of Medicine, Charles University, 18081 Prague, Czech Republic; michal.zikan@lf1.cuni.cz

12 Laboratory of Cancer Cell Biology, Institute of Molecular Genetics of the Czech Academy of Sciences, 14220 Prague, Czech Republic; libor.macurek@img.cas.cz

* Correspondence: jana.soukupova@lf1.cuni.cz; Tel.: +420-224965739

Received: 15 March 2020; Accepted: 10 April 2020; Published: 13 April 2020 
$B R I P 1$ and NBN were associated with moderate risk (both $\mathrm{OR}=3.5$ ). BRCA1/2 mutations dominated in almost all clinicopathological subgroups including sporadic borderline tumors of ovary (BTO). Analysis of remaining 201 genes revealed somatic mosaics in PPM1D and germline mutations in SHPRH and NAT1 associating with a high/moderate OC risk significantly; however, further studies are warranted to delineate their contribution to OC development in other populations. Our findings demonstrate the high proportion of patients with hereditary OC in Slavic population justifying genetic testing in all patients with OC, including BTO.

Keywords: ovarian cancer; next-generation sequencing; predisposition genes; cancer risk; mutation

\section{Introduction}

Ovarian cancer (OC) is the most severe gynecologic malignancy with stable incidence and mortality. The most frequent OC types (85-95\%) are epithelial tumors, which are high-grade (HG) serous in 70\% of cases [1,2]. Because of the nonspecific symptoms and a lack of presymptomatic screening modalities, most women are diagnosed with an advanced disease, having a dismal 25\% 5-year survival rate [3].

The overall OC lifetime risk oscillates around $2 \%$ in the general female population in developed countries. Central and Eastern Europe, including the Czech Republic, represented a region with the highest OC incidence (11.9 ASRW per 100,000 females) and mortality (6.0 ASRW per 100,000 females) worldwide in 2018 (http://gco.iarc.fr). In the Czech Republic alone, annual OC incidence and mortality in 2018 reached 9.5 and 6.7 ASRW per 100,000 females, respectively.

Genetic predisposition for OC is unusually high and is reported in up to $25 \%$ of cases [4-6]. The most frequent germline mutations affect the BRCA1 and BRCA2 genes, conferring $24 \%$ and $8.4 \%$ OC lifetime risks, respectively [7]. The BRCA1 and BRCA2 mutation carriers frequently but not exclusively develop HG serous OC [8]. Carriers of mutations in these major OC predisposition genes have also very high risk of breast cancer $(\mathrm{BC})$ development. A high OC risk has also been associated with germline mutations in RAD51C, RAD51D, Lynch syndrome genes, and STK11; a moderate OC risk with BRIP1 [9-13]. Risks associated with germline mutations in genes with anticipated $B C$ and/or OC predisposition (incl. ATM, BARD1, CDH1, CHEK2, NBN, PALB2, PTEN, and TP53) and in other candidate genes remain to be determined [14-17]. The identification of presymptomatic women at high risk who can benefit from risk-reducing salpingo-oophorectomy (RRSO) is of critical importance, as demonstrated by the reduced OC mortality in BRCA1 and BRCA2 mutation carriers undergoing preventive surgery [18].

In this report, we aim to establish an association of germline mutations with OC in the Czech patients belonging to the Slavic population that has not been systematically analyzed for OC predisposition. Seven Czech genetic laboratories participated in the analysis of $1333 \mathrm{Czech}$ OC patients by the identical procedure using CZECANCA panel (CZEch CAncer paNel for Clinical Application) targeting 219 genes [19]. Prevalence of variants in genes affected in OC patients was assessed in 2278 population-matched controls. This analysis enabled us to comprehensively determine mutations frequency and clinicopathological characteristics of OC in carriers of mutations in genes with known OC predisposition but also to analyze contribution of population-specific variants in other candidate genes to OC predisposition.

\section{Results}

\subsection{Description of Study Population}

Altogether, samples obtained from 1333 OC patients diagnosed at seven centers were analyzed by the identical panel NGS using the CZECANCA panel targeting 219 cancer-predisposition and candidate genes and were evaluated centrally by the identical bioinformatics pipeline. From 1333 
analyzed OC patients, 1045 (78.4\%) women were diagnosed with OC only and $288(21.6 \%)$ women with double primary tumors, including BC (210 patients; $15.8 \%$ ) or other tumors (78 patients; $5.9 \%$ ). The median age at OC diagnosis was 53.7 years (range 15-86 years). Almost half (47.6\%) of the patients had a negative family cancer history. From 1120 OC patients with known histology, 728 (65.0\%) women developed serous adenocarcinoma with prevailing HG tumors. Sixty percent of cases represented patients with advanced disease (stages III-IV). The clinicopathological characteristics are provided in Table S1.

\subsection{Mutations in 18 Known/Anticipated Hereditary BC/OC Genes}

We primarily focused on mutations in 18 BC/OC genes listed in the NCCN Guidelines for Genetic/Familial High-Risk Assessment: Breast, Ovarian, and Pancreatic (Version 1.2020; 4 December 2019). We identified 441 mutations in 427/1333 (32.0\%) OC patients and 58/2278 (2.5\%) mutation carriers among population-matched controls (PMC) in 18 known/anticipated BC/OC genes (Figure 1, Table 1, and Table S2). Thirteen multiple mutation carriers (Figure 1) identified among patients only (characterized in Table S3) were excluded from the subsequent analyses.

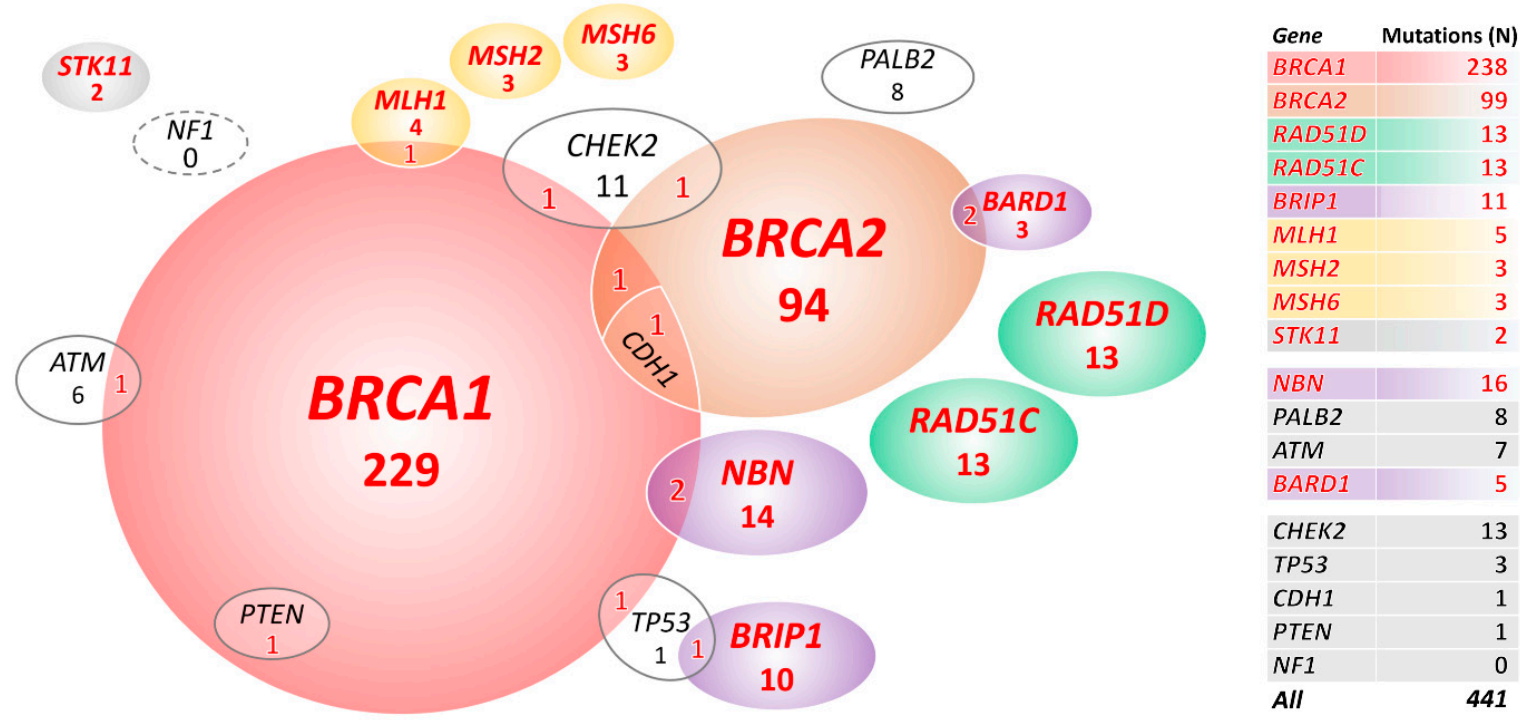

Figure 1. Overall, 427 mutation carriers of 441 mutations in 18 known/anticipated breast cancer (BC)/ovarian cancer (OC) predisposition genes. In total, 399 carriers in genes significantly associated with OC in our study are highlighted in red letters. STK11 is highlighted as rarely mutated but established OC predisposition gene.

Carriers of germline mutations in 10 genes (including Lynch syndrome genes analyzed as a group together) had significantly increased OC risk (Table 1 in bold). We found the prevailing BRCA1 or BRCA2 germline alterations in 323/1320 (24.5\%) patients and in 12/2278 (0.5\%) PMC. Further, 65/1320 $(4.9 \%)$ OC patients carried a mutation in 8 other genes significantly associated with OC risk in our study (including 2 carriers of mutations in STK11, an established high-risk OC gene that did not reach significant association in our study due to low frequency of mutation carriers in patients; Figure 1). We found only 19/2278 (0.8\%) carriers of mutations in these 8 genes in PMC. 
Table 1. Mutation frequencies in 1320 ovarian cancer cases and in 2278 population-matched controls (PMC).

\begin{tabular}{|c|c|c|c|}
\hline Gene & $\begin{array}{c}1320 \text { OC Patients } \\
\text { N Mutations ( } \%)\end{array}$ & $\begin{array}{c}2278 \text { PMC } \\
\text { N mutations (\%) }\end{array}$ & OR $(95 \% \mathrm{CI}) ; \mathrm{p}^{(a)}$ \\
\hline \multicolumn{4}{|c|}{ Increased OC risk ${ }^{(b)}$} \\
\hline$B R C A 1^{(\mathrm{c})}$ & 229 (17.35) & $5(0.22)$ & $95.2(40.1-295.2) ; 1.83 \times 10^{-97}$ \\
\hline$B R C A 2^{(c)}$ & $94(7.12)$ & $7(0.31)$ & $24.9(11.6-63.6) ; 1.16 \times 10^{-33}$ \\
\hline$R A D 51 D$ & $13(0.98)$ & $2(0.09)$ & $11.3(2.6-103.4) ; 9.66 \times 10^{-5}$ \\
\hline RAD51C & $13(0.98)$ & $4(0.18)$ & $5.7(1.7-23.8) ; 0.001$ \\
\hline$B R I P 1^{(c)}$ & $10(0.76)$ & $5(0.22)$ & 3.5 (1.1-13); 0.03 \\
\hline$M L H 1^{(c)}$ & $4(0.3)$ & $1(0.04)$ & $6.9(0.7-340.4) ; 0.06^{(\mathrm{d})}$ \\
\hline MSH2 & $3(0.23)$ & 0 & $0.049^{(d)}$ \\
\hline MSH6 & $3(0.23)$ & 0 & $0.049^{(d)}$ \\
\hline STK11 & $2(0.15)$ & 0 & 0.13 \\
\hline \multicolumn{4}{|c|}{ Potentially increase or insufficient evidence OC risk ${ }^{(b)}$} \\
\hline$N B N^{(c)}$ & 14 (1.06) & $7(0.31)$ & 3.5 (1.3-10.2); 0.006 \\
\hline PALB2 & $8(0.61)$ & $9(0.40)$ & $1.5(0.5-4.5) ; 0.45$ \\
\hline$A T M^{(c)}$ & $6(0.45)$ & $8(0.35)$ & $1.3(0.4-4.3) ; 0.78$ \\
\hline$B A R D 1^{(c)}$ & $3(0.23)$ & 0 & 0.049 \\
\hline \multicolumn{4}{|c|}{ No increased risk of $\mathrm{OC}^{(\mathrm{b})}$} \\
\hline CHEK2 ${ }^{(c)}$ & $11(0.83)$ & $8(0.35)$ & $2.4(0.9-6.8) ; 0.06$ \\
\hline TP53(c) & $1(0.08)$ & $2(0.09)$ & $0.9(0-16.6) ; 1$ \\
\hline$C D H 1^{(\mathrm{c})}$ & 0 & 0 & - \\
\hline PTEN (c) & 0 & 0 & - \\
\hline NF1 & 0 & 0 & - \\
\hline
\end{tabular}

The copy number variation (CNV) analysis in $18 \mathrm{OC} / \mathrm{BC}$ genes revealed 37 large genomic rearrangements in 37/1333 (2.8\%) patients. They affected seven genes $(23 \times B R C A 1,4 \times B R I P 1,4 \times C H E K 2$, $2 \times M L H 1,2 \times S T K 11,1 \times P A L B 2$, and $1 \times C D H 1)$ and accounted for $8.4 \%(37 / 441)$ of all pathogenic mutations in these genes. Except 1 whole gene duplication of MSH6 (classified as VUS), we found no $\mathrm{CNV}$ in analyzed controls in these 18 genes.

\subsection{Clinical and Histopathological Characteristics of Mutation Carriers}

Subsequently, we described the clinicopathological characteristics of the mutation carriers in 10 genes associated with OC risk (Figure 2 and Table S4). Multiple mutation carriers (Table S3) were excluded from this analysis.

\subsubsection{Age at OC Diagnosis}

The highest mutation frequency was found in patients diagnosed with OC at 40-49 and 50-59 years (37.4\% and $40.7 \%$, respectively) and the lowest in patients diagnosed before the age of 30 (8.3\%; Figure 2A). Interestingly, the mutation frequency in the group of the oldest patients ( $\geq 70$ years) was twice higher than in the youngest ( $<30$ years) patients' subgroup ( $p=0.013$ for difference). 
This difference was primarily caused by BRCA1/BRCA2 mutations ( $3.6 \%$ vs. $18.1 \%$ in patients $<30$ vs. $\geq 70$ years), as the frequency of non-BRCA genes mutations was similar ( $4.8 \%$ vs. $4.3 \%)$. The median age at diagnosis was significantly different in BRCA1 (51.0 years; range 23-78) and BRCA2 (58.4 years; range $27-78)$ mutation carriers $\left(p=8.5 \times 10^{-10}\right)$, respectively. The median age at diagnosis in other genes with at least 10 identified mutation carriers increased gradually from $R A D 51 C$ (52.2 years; range 25-69) to NBN (54.5 years; range 18-76), RAD51D (56.0 years; range 36-69), and BRIP1 (58.0 years; range 30-71). We observed a younger median age at diagnosis in carriers of mutations in Lynch syndrome genes 46.0 years (range $35-73$ ).
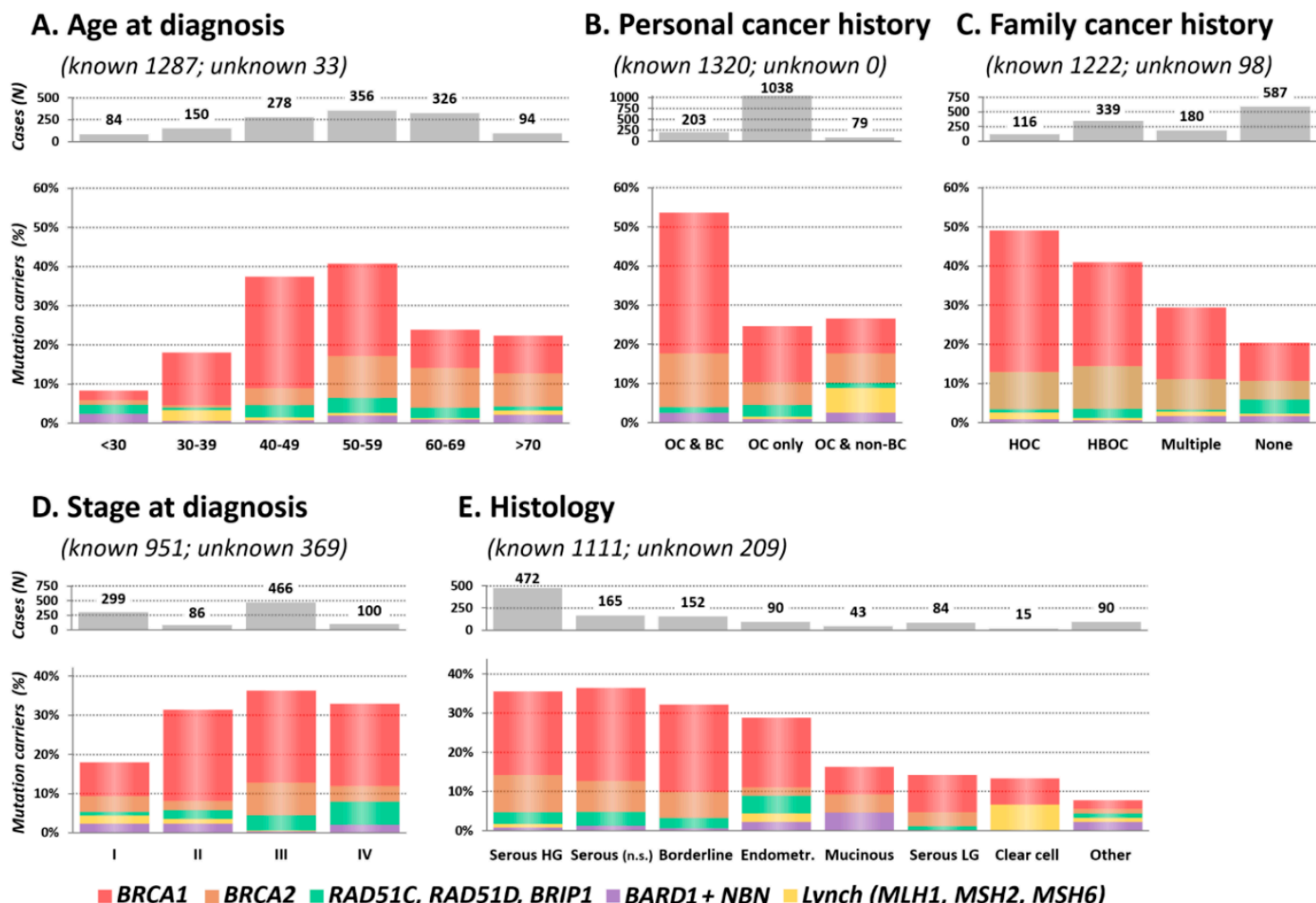

Figure 2. Proportion of mutation carriers in clinicopathological subgroups, including (A) Age at OC diagnosis; (B) Personal cancer history; (C) Family cancer history; (D) Stage at diagnosis; (E) Histology in 1320 OC patients.

\subsubsection{Personal and Family Cancer History}

The highest proportion of mutations (109/203; 53.7\%) was detected in double primary OC and $\mathrm{BC}$ patients, while in patients diagnosed with $\mathrm{OC}$ only and double primary OC and non-BC cancer, it reached 256/1038 (24.7\%) and 21/79 (26.6\%), respectively (Figure 2B). The frequency of mutations in patients from hereditary OC families (HOC) was 49.1\% (57/116; Figure 2C). Decreasing proportion of mutation carriers in other family cancer history categories (41.0\% in HBOC and $29.4 \%$ in multiple cancer) was dominantly caused by decreasing BRCA1 mutation prevalence. Nevertheless, in 587 OC patients without a positive family cancer history, we still identified $120(20.4 \%)$ carriers of pathogenic mutations.

\subsubsection{Stage and Histology}

Almost $60 \%$ of patients were diagnosed at FIGO stage III or IV (Figure 2D). In contrast, 6/8 informative Lynch syndrome gene mutation carriers were diagnosed with stage I tumors.

The mutation rate stratified OC into two histological clusters. The high mutation rate subgroup included 879 patients with HG/unspecified serous, borderline, and endometrioid tumors with 303 $(34.5 \%)$ carriers, while the low mutation rate subgroup included 232 patients with low-grade (LG) 
serous, mucinous, clear cell, and other tumors with $28(12.1 \%)$ carriers. BRCA1/2 mutations in HG serous carcinomas were more than twice as frequent $(146 / 472 ; 30.9 \%)$ as in LG serous ones (11/84; $13.1 \%)$. Interestingly, the distribution of $B R I P 1 / R A D 51 C / R A D 51 D$ mutations among histological types was similar to that of $B R C A 1 / 2$. The lowest proportion of mutations $(7 / 90 ; 7.8 \%)$ was found in rare histological cancer types (herein denominated as "Other").

\subsection{Mutations in Additional 201 Analyzed Genes}

Finally, we reviewed the presence of germline variants in additional 201 genes targeted by the CZECANCA panel [19]. This analysis revealed 230 mutations in 89 genes in $208(15.6 \%)$ patients (Table S5). Of these, 149 (11.2\%) patients carried mutations in "additional" genes exclusively while $59(4.4 \%)$ patients carried a mutation in "additional" genes alongside a mutation in one of the 10 OC risk genes. Mutations in these "additional" genes were rare and their prevalence was significantly higher in patients over controls in only four genes (Table 2). However, only mutations in PPM1D were significantly associated with OC risk $(p=0.003)$ following Bonferroni correction and exclusion of carriers of mutations in OC predisposition genes. All PPM1D mutations were mosaic with MAF = $14 \%-60 \%$ and MAF $=17 \%-19 \%$ in patients and controls, respectively. It should be noted that blood for genetic testing was sampled after the application of chemotherapy in all PPM1D positive patients (in average at 38 months after treatment; ranged 4 months-7.1 years). Seven out of 15 PPM1D mutation carriers harbored an additional mutation in another DNA repair gene $(3 \times B R C A 2,1 \times P A L B 2,1 \times E X O 1$, and $1 \times P M S 1)$. MAF of PPM1D mutations correlated neither with age at OC diagnosis nor with the time from the last chemotherapy (Table S6). Mutations in PPM1D and SHPRH were significantly associated only with age $>60$ years $(p=0.001)$, whereas frequency of NAT1 mutations in particular categories was similar (Table S7). Uncorrected p values were marginally significant also for germline variants in MMP8 and FANCG in OC patients when carriers of mutations in $10 \mathrm{BC} / \mathrm{OC}$ predisposition genes significantly associating with OC risk in our study were excluded (Table 2).

Table 2. Additional 201 analyzed genes significantly associated with OC risk in the group of all OC patients and in a subgroup of 934 patients without mutations in 10 established OC predisposition genes.

\begin{tabular}{|c|c|c|c|}
\hline Gene & $\begin{array}{c}\text { Patients N } \\
\text { Mutations (\%) }\end{array}$ & $\begin{array}{c}2278 \text { PMC N } \\
\text { Mutations (\%) }\end{array}$ & OR $(95 \% \mathrm{CI}) ; \mathrm{p}$ (Bonferroni Corrected $p)$ \\
\hline \multicolumn{4}{|c|}{ All 1333 OC patients } \\
\hline PPM1D & $16(1.20)$ & $2(0.09)$ & $13.82(3.24-124.22) ; 7.4 \times 10^{-6}(0.001)$ \\
\hline NAT1 & $13(0.98)$ & $5(0.22)$ & 4.48 (1.49-16.07); 0.003 (n.s.) \\
\hline SHPRH & $5(0.38)$ & $1(0.04)$ & 8.57 (0.96-404.83); 0.028 (n.s.) \\
\hline \multicolumn{4}{|c|}{934 OC patients without mutations in 10 genes significantly associated with OC in our study } \\
\hline PPM1D & $12(1.28)$ & $2(0.09)$ & $14.80(3.28-136.67) ; 1.7 \times 10^{-5}(0.003)$ \\
\hline NAT1 & $8(0.86)$ & $5(0.22)$ & 3.96 (1.13-15.30); 0.026 (n.s.) \\
\hline MMP8 & $6(0.64)$ & $4(0.18)$ & 3.67 (0.87-17.74); 0.041 (n.s.) \\
\hline FANCG & $5(0.53)$ & $2(0.09)$ & 6.12 (1.00-64.45); 0.025 (n.s.) \\
\hline
\end{tabular}

\section{Discussion}

The analysis of 1333 Czech OC patients and 2278 population-matched controls provides the most comprehensive view of the genetic architecture of OC predisposition in the Slavic population. From 18 OC/BC predisposition genes listed in current NCCN breast/ovarian familial cancer guidelines, mutations in 10 genes were significantly associated with OC risk in our population being present in 399/1333 (29.9\%) OC patients and 31/2278 (1.4\%) PMC (Figure 1). Mutations in eight remaining genes were extremely rare (CDH1, PTEN, STK11, and TP53) or absent (CDKN2A and NF1) or did not significantly differ in frequency among cases and controls (ATM, PALB2, and CHEK2). Mutations in $B R C A 1 / 2, R A D 51 C / D$, and Lynch syndrome genes were associated with a high OC risk, while mutations in BRIP1 were associated with a moderate OC risk in our study (Table 1), in concordance with previous 
reports $[9,10,20,21]$. The $B R C A 1$ and $B R C A 2$ mutations, present in $84.0 \%$ of all mutation carriers, were by far the most frequent alterations found in $17.9 \%$ and $7.4 \%$ of our patients, respectively. Mutations in other eight genes leaded by RAD51C/RAD51D/BRIP1 affected additional $5.0 \%$ of patients, as shown also by others recently [5,6,22]. Germline mutations in Lynch syndrome genes together associated with high OC risk. Mutations in MLH1 prevailed similarly as in Lynch syndrome patients diagnosed with colorectal cancer [23].

In contrast to previous studies, our results suggest increased OC risk in carriers of NBN and $B A R D 1$ mutations [12,24]. We did not find significant increase of OC risk for carriers of mutations in $A T M$ and PALB2, as noticed previously $[12,24,25]$. However, further analyses considering very large population-matched studies or studies considering families of mutation carriers can better disclose moderate risk associations, as shown for PALB2 mutations recently [26].

Overrepresentation of mutations in the CHEK2 gene in OC patients in this study was marginally nonsignificant in contrast to our previous report where we identified moderately increased OC risk for CHEK2 mutation carriers [27]. However, last four CHEK2 coding exons were not targeted in our gene panel omitting possible deleterious CHEK2 alterations identified in our previous study in which last four coding exons were analyzed separately in both cases and controls. Mutations in NF1 were absent and were extremely rare in CDH1 and PTEN, just like STK11 mutations found in a patient with nonepithelial OC, a characteristic Peutz-Jeghers syndrome manifestation [9]. Altogether, the high overall frequency of mutations in OC predisposition genes in our study is in agreement with some previous studies $[4-6,28]$ and may contribute to a high OC incidence in our population.

Multigene testing revealed 13 carriers of multiple pathogenic mutations (1.0\% of patients). Similar frequency of individuals with this multilocus inherited neoplasia alleles syndrome (MINAS) [29] was shown also in previous analyses of OC patients [30,31].

We analyzed available phenotype characteristics in 1320 OC patients with one pathogenic mutation at the most in 10 genes associated with OC risk in our study (Figure 2). While the highest prevalence of $B R C A 1 / 2$ mutation carriers was in patients diagnosed with double primary $\mathrm{OC}$ and $\mathrm{BC}$, mutations in $R A D 51 C / R A D 51 D / B R I P 1$ prevailed in patients diagnosed with OC only (Figure 2B); nevertheless, their distribution among histological subtypes was similar to that in $B R C A 1 / 2$ mutation carriers (Figure 2E). In contrast to Castera et al. who found mutations in RAD51C/RAD51D/BRIP1 dominantly in French OC patients with a positive family OC history [32], we identified mutations in these genes in $1 / 116(0.9 \%)$ and $22 / 587(3.7 \%)$ carriers in HOC patients and in patients with a negative family cancer history, respectively. Further, we have noticed a surprisingly high frequency of OC-predisposing mutations in older patients. Their prevalence in patients $\geq 60$ years was $23.6 \%$, whereas Harter et al. found in this age group $18.9 \%$ mutation carriers even though frequency of mutation carriers in patients $<60$ years in both studies was comparable (32.6\% and $33.2 \%$, respectively) [28]. BRCA1 mutations dominated in patients $<60$ years over $B R C A 2$ mutations, while in patients $\geq 60$ years, their frequencies were comparable. Moreover, we revealed 29 BRCA1/2 mutation carriers (13.9\% of patients) in 208 OC patients diagnosed at $\geq 60$ years with no family cancer history, while Morgan and colleagues detected only two (4.3\%) BRCA1/2 mutations in 46 sporadic OC patients $\geq 60$ years [33]. Even in the oldest subgroup of our OC patients diagnosed at $\geq 70$ years, the frequency of $B R C A 1 / 2$ mutation carriers exceeded $18 \%$, while in other studies, $B R C A 1 / 2$ mutations' frequency in this age category was below $10 \%[34,35]$. This high frequency of $B R C A 1 / 2$ mutations in our patients $\geq 70$ years contrasted with a low frequency in women diagnosed at $<30$ years ( $18.1 \%$ vs. $3.6 \% ; p=0.003$; Figure $2 \mathrm{~A}$ ). The difference was even more apparent in "sporadic" OC cases (with no family cancer history), where BRCA1/2 mutations were found in 6 out of 45 (13.3\%) women $\geq 70$ years but in none of 52 cases diagnosed at $<30$ years. It should be emphasized that although rare histological OC types were more frequent in the subgroup of 52 patients diagnosed with sporadic OC at $<30$ years, 32 (65.3\%) of 49 informative cases developed invasive epithelial OC.

Mutations in OC predisposition genes significantly prevailed in subgroups with high-grade/ nonspecified serous, borderline, and endometrioid tumors over subgroup with low-grade serous, 
mucinous, clear cell, or other rare histologic types (Figure 2E). Surprisingly, the overall mutation frequency in patients with borderline tumors was comparable with that of in HG serous OC $(32.2 \%$ and $36.7 \%$, respectively; Figure 2E). Thus, we compared mutation frequency in patients with no family cancer history diagnosed with these histological tumor types, and we found that although the mutation frequency in sporadic borderline tumors was half in comparison to sporadic HG serous (Figure 3), it still largely exceeded $10 \%$ in both hereditary and sporadic cases, justifying the genetic testing of borderline tumors. The large proportion of borderline tumors with positive family cancer history in our study suggested that this OC subtypes belong to a possible manifestation of a cancer predisposition. However, our observation needs to be confirmed in other populations as current reports about borderline tumors in $B R C A 1 / 2$ mutation carriers are limited.
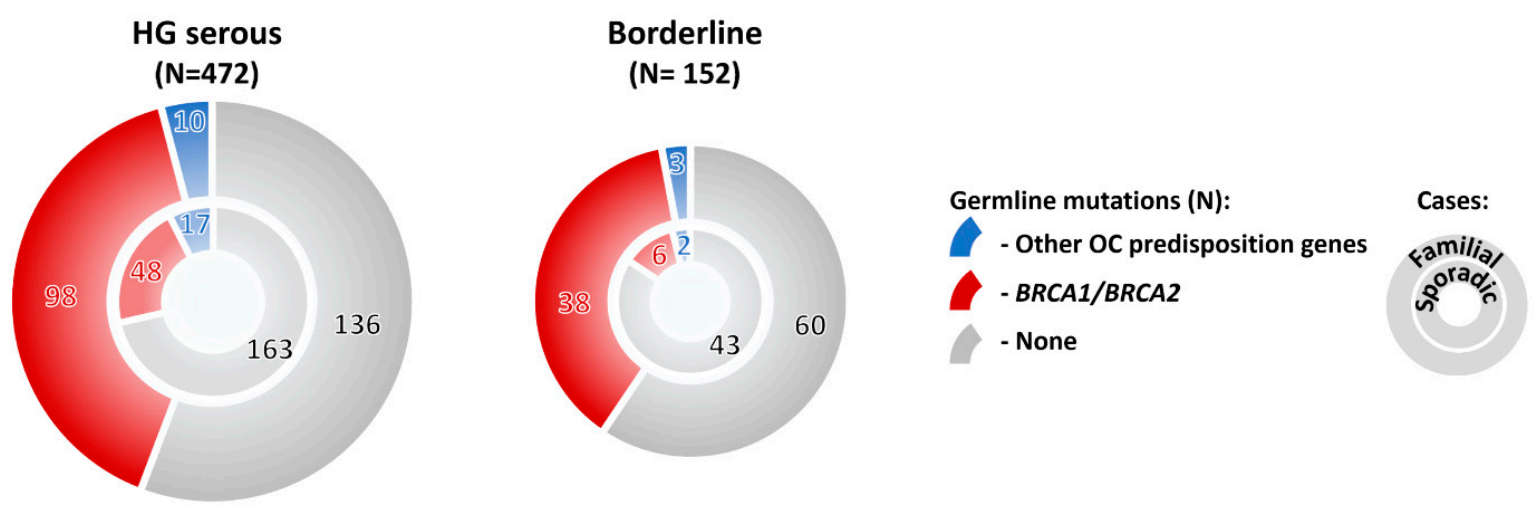

Figure 3. Frequency of mutations in $10 \mathrm{BC} / \mathrm{OC}$ predisposition genes significantly associated with OC in our study in OC patients with high-grade (HG) serous and borderline tumors, respectively. The patients were subdivided into subgroups with positive (familial cases) and negative (sporadic cases) family cancer history, respectively.

The multigene panel enabled us to identify other candidate genes associating with increased OC risk. We noticed many rare truncating variants episodically affecting various genes and clustering into PPM1D, NAT1, and SHPRH in OC patients. The PPM1D gene, coding for WIP1 phosphatase, was the only candidate associated with OC risk following multiple testing correction. Similarly to the previous studies describing its mosaic variants in OC patients [36-38], we also found mosaic gain-of-function mutations resulting in increased WIP1 phosphatase activity [38]. All PPM1D mutations in our patients were identified in postchemotherapy treatment blood samples suggesting their somatic origin [39]. Germline mutations in NAT1 have not been analyzed for OC predisposition so far. However, several polymorphisms in NAT1 (coding for arylamine $\mathrm{N}$-acetyltransferase 1 engaged in carcinogen metabolism and detoxification) were shown to modify the risk of various cancers $[40,41]$. The SHPRH gene codes for E3 ubiquitin-protein ligase targeting PCNA upon DNA damage [42]. Contribution of SHPRH germline variants to $\mathrm{OC}$ risk remains elusive. Overall, low mutation frequencies found in gene candidates in our study precluded its precise OC risk estimations and will require large, multiethnic, case-control studies, segregation analyses in affected families, and functional analyses. Alongside variants clustering to a few candidate genes, we identified rare mutations in a gene family coding for Fanconi anemia (FA) proteins involved in the repair of DNA interstrand crosslinks [43]. Several FA genes belong to established OC predisposition genes, including BRCA1 (FANCS), BRCA2 (FANCD1), RAD51C (FANCO), PALB2 (FANCN), and BRIP1 (FANCJ). Except these, we found rare mutations in other FA genes (FANCG, FANCD2, and FANCA) in $11(0.83 \%)$ of $1333 \mathrm{OC}$ patients compared to 5 in 2278 PMC $(0.2 \%)$, with cumulative $\mathrm{OR}=3.78(95 \% \mathrm{CI} 1.21-13.91 ; p=0.02)$. Interestingly, these rare mutations were detected almost exclusively in patients without mutations in other OC predisposition genes.

The strengths of this study include an identical NGS analysis and bioinformatics pipeline in all patients, a careful curation of clinical data, and an ethnically homogeneous set of patients and controls representing the largest sample set from the region of Central and Eastern Europe. Despite 
that, the number of individuals still did not allow the precise OC risk calculations in rarely mutated genes. Although all OC cases in the Czech Republic are eligible for genetic testing, OC patients with positive family cancer history and earlier-onset individuals were enriched in our study, especially in a small subgroup enrolled before 2015 (in the Center A only).

Whether the high prevalence of clinically important germline mutations in OC patients justifies population-wide screening is a vivid matter of debate [44-48]. We emphasize that we found BRCA1/2 mutations in $14.5 \%$ of OC patients with no family cancer history who would currently not be revealed presymptomatically without population screening. We assume that careful application of germline testing in all OC patients and their relatives would reduce OC burden in our population. Moreover, the mutations in BRCA1/2 [49,50] and other OC predisposition genes [51,52] represent valuable predictive biomarkers improving OC chemotherapy.

\section{Materials and Methods}

Analyzed patients $(N=1333)$ were enrolled in 2010-2018 and included all OC cases regardless of familial cancer history or OC histology subtypes. As knowledge about germline mutations' frequency in women diagnosed with BTO is limited, we included these histological subtypes to our study. Clinicopathological data were obtained during genetic counselling or retrieved from the patients' records. OC patients with a positive cancer family history were stratified into (i) hereditary ovarian cancer (HOC) families with OC and other nonbreast cancer (BC) in the family history; (ii) hereditary breast and/or ovarian cancer (HBOC) families with BC and OC or other cancer in the family history, and (iii) multiple cancer families with non-OC and non-BC in the family history. Index patients were tested in seven centers: (A) First Faculty of Medicine, Charles University, Prague $(N=637)$; (B) Masaryk Memorial Cancer Institute, Brno ( $N=357)$; (C) Gennet, Prague ( $N=273)$; (D) AGEL Laboratories, Novy Jicin $(N=34)$; $(\mathrm{E})$ GHC Genetics $(N=12)$; $(\mathrm{F})$ Pronatal $(N=11)$, and $(\mathrm{G})$ University Hospital Olomouc $(N=9)$.

Population-matched controls (PMC; $N=2278$ ) included 616 noncancer controls collected in centers A $(N=344), \mathrm{B}(N=150)$, and $\mathrm{D}(N=122)$, and 1662 unselected controls provided by the National Center for Medical Genomics (http://ncmg.cz). The noncancer controls were volunteers (78 males and 538 females) aged $\geq 60$ years without a personal or family cancer history (in first-degree relatives). The unselected controls (1170 males and 492 females; median age 57 years, range 18-88 years) were unrelated individuals analyzed by whole-exome sequencing (WES) for various noncancer conditions.

All patients and controls were Caucasians of a Czech origin. Written informed consent was obtained from all patients and controls. The study was approved by the Ethics Committee of the General University Hospital in Prague; ethics approval number was 92/14. The study was performed in accordance with the Declaration of Helsinki.

\subsection{Next-Generation Sequencing}

Germline blood-derived DNA was analyzed by the CZECANCA (CZEch CAncer paNel for Clinical Application; custom-made SeqCap EZ choice panel; Roche) panel NGS targeting 219 genes on MiSeq (Illumina), as described in details previously [19]. Sequencing reads were aligned by Novoalign v2.08.03 to the human reference genome (hg19). Variants were identified using GATK and Pindel, CNVs using CNV score [19]. The entire diagnostic pipeline was successfully tested using European Molecular Genetics Quality Network schemes (EMQN) and validated as we have described recently [19].

\subsection{Variant Classification}

We first analyzed 18 genes considered clinically relevant to the HBOC syndrome (MIM \#604370) by NCCN, namely, ATM, BARD1, BRCA1, BRCA2, BRIP1, CDH1, CHEK2, MLH1, MSH2, MSH6, NBN, PALB2, PTEN, RAD50, RAD51C, RAD51D, STK11, and TP53. Germline variants (with frequency $\leq$ 0.01 and $\leq 0.05$ in 1000 Genomes project and noncancer PMC, respectively) were classified into three 
groups: i) pathogenic/likely pathogenic, ii) variants of unknown significance (VUS), and iii) likely benign/benign, based on recommendations from the ENIGMA consortium (https://enigmaconsortium. org). All nonsense/frameshift/splicing ( $\pm 1-2 \mathrm{bp}$ ) mutations/CNVs were considered pathogenic/likely pathogenic unless classified as other in the ClinVar database; whole gene duplications were considered VUS. The other types of mutations were considered pathogenic/likely pathogenic only if classified as such in ClinVar by at least two submitters. TP53 variants were classified using the IARC TP53 database (http://p53.iarc.fr/), CHEK2 VUS using a recently published functional assay [27].

Subsequently, we analyzed variants in another 201 genes targeted by the CZECANCA panel. Nonsense/frameshift/splicing $( \pm 1-2 \mathrm{bp}$ ) mutations/CNVs (except whole gene duplications) with frequency $\leq 0.01$ and $\leq 0.05$ in 1000 Genomes project and in noncancer PMC, respectively, were considered pathogenic.

All pathogenic/likely pathogenic mutations in patients and noncancer PMC were confirmed by Sanger sequencing and CNVs by MLPA (if available) or by qPCR (protocol available on request), and they were submitted to ClinVar under the submission ID SUB5822876.

\subsection{Statistical Analysis}

The odds ratio (OR) for particular gene was calculated using Fisher's exact test, and $\mathrm{p}$ values $<0.05$ were considered significant. The multiple mutation carriers were excluded from the OR calculations. For the identification of other OC candidate genes, the Bonferroni correction was employed. The associations between mutation status and clinicopathological characteristics were estimated using Fisher's exact test, and $p$ values $<0.05$ were considered significant.

\section{Conclusions}

Our study demonstrated that nearly one in three OC patients carries a pathogenic mutation in genes significantly associated with OC. The mutation frequency exceeded $10 \%$ in all clinicopathological subgroups, regardless of the age at diagnosis, clinical or histopathological characteristics, with an exception of women diagnosed with OC before the age of 30 or with rare histological OC subtypes. Importantly, we found that the high mutation prevalence included borderline tumors justifying genetic testing of all OC patients, including women diagnosed with borderline tumors. Surprisingly, $B R C A 1 / 2$ mutations were not associated with sporadic OC in very young women ( $\leq 30$ years). Besides the established OC predisposition genes, NBN and BARD1 were significantly associated with a moderate OC risk; however, further studies will be required to specify the associated $\mathrm{OC}$ risk and to identify the value of the detected genetic mutations in terms of disease prognosis and therapy prediction. Hence, analyses of rarely mutated BC/OC predisposition genes that failed to increase OC risk in our study are further warranted to evaluate their association with OC in future larger dataset and/or in frame of international consortia. These should include also other candidate alterations with predictive and/or prognostic potential.

Supplementary Materials: The following are available online at http://www.mdpi.com/2072-6694/12/4/956/s1, Table S1: the clinicopathological characteristics of 1333 ovarian cancer patients, Table S2: mutation frequencies in ovarian cancer cases and population-matched controls, Table S3: clinical and pathological characteristics in multiple mutation carriers, Table S4: clinicopathological characteristics of mutation carriers in HBOC genes listed in NCCN guidelines (mutation carriers in a group of 1320 ovarian cancer patients (after exclusion of 13 multiple mutation carriers shown in Table S3) (10 genes significantly associated with OC risk in our study are highlighted), Table S5: mutations in 201 additional analyzed genes with associated OC risk (significantly associated genes $(p<0.05)$ are highlighted), Table S6: characteristics of 15 PPM1D mutation carriers, and Table S7: clinicopathological characteristics of mutation carriers in NAT1, PPM1D, and SHPRH significantly associated with OC risk.

Author Contributions: Conceptualization, J.S.; data curation, M.V., L.F., and M.K.; funding acquisition, P.K., Z.K., and J.S.; investigation, K.L., L.S., M.J., M.B., M.C., S.J., J.K., Z.V., M.U., P.K., E.M., L.F., J.H., P.V., F.L., M.K., L.C., S.T., J.I., L.H., M.K., R.V., S.K., M.Z., L.M., Z.K., and J.S.; methodology, K.L., Z.K., and J.S.; project administration, J.S.; resources, P.K., R.V., S.K., Z.K., and J.S.; software, P.Z. and V.S.; validation, K.L., L.S., M.J., M.B., M.C., E.M., F.L., S.T., and J.S.; writing—original draft, K.L., Z.K., and J.S.; writing-review and editing, L.S., P.Z., M.V., M.J., M.B., P.K., E.M., L.F., F.L., and L.M. All authors have read and agreed to the published version of the manuscript. 
Funding: This research was funded by the Ministry of Health of the Czech Republic [Grant numbers 16-29959A, NV17-32030A, NV18-03-00024, MH CZ - DRO (FNOl, 00098892)] and by the Charles University projects [SVV 260516, PROGRES Q28/LF1, CZ.02.1.01/0.0/0.0/16_013/0001634].

Acknowledgments: We thank our patients for contribution in this study. We thank our clinical colleagues for their valuable comments to the manuscript and Jan Flemr for language editing.

Conflicts of Interest: The authors have declared no conflicts of interest.

\section{References}

1. Levanon, K.; Crum, C.; Drapkin, R. New insights into the pathogenesis of serous ovarian cancer and its clinical impact. J. Clin. Oncol. 2008, 26, 5284-5293. [CrossRef] [PubMed]

2. Kim, J.; Park, E.Y.; Kim, O.; Schilder, J.M.; Coffey, D.M.; Cho, C.H.; Bast, R.C., Jr. Cell Origins of High-Grade Serous Ovarian Cancer. Cancers (Basel) 2018, 10, 433. [CrossRef] [PubMed]

3. Siegel, R.L.; Miller, K.D.; Jemal, A. Cancer statistics, 2016. CA A Cancer J. Clin. 2016, 66, 7-30. [CrossRef] [PubMed]

4. Walsh, T.; Casadei, S.; Lee, M.K.; Pennil, C.C.; Nord, A.S.; Thornton, A.M.; Roeb, W.; Agnew, K.J.; Stray, S.M.; Wickramanayake, A.; et al. Mutations in 12 genes for inherited ovarian, fallopian tube, and peritoneal carcinoma identified by massively parallel sequencing. Proc. Natl. Acad. Sci. USA 2011, 108, 18032-18037. [CrossRef] [PubMed]

5. Koczkowska, M.; Krawczynska, N.; Stukan, M.; Kuzniacka, A.; Brozek, I.; Sniadecki, M.; Debniak, J.; Wydra, D.; Biernat, W.; Kozlowski, P.; et al. Spectrum and Prevalence of Pathogenic Variants in Ovarian Cancer Susceptibility Genes in a Group of 333 Patients. Cancers (Basel) 2018, 10, 442. [CrossRef] [PubMed]

6. Krivokuca, A.; Boljevic, I.; Jovandic, S.; Magic, Z.; Mandic, A.; Tomasevic, Z.; Brankovic-Magic, M. Germline mutations in cancer susceptibility genes in high grade serous ovarian cancer in Serbia. J. Hum. Genet. 2019. [CrossRef]

7. Offit, K. BRCA mutation frequency and penetrance: New data, old debate. J. Natl. Cancer Inst. 2006, 98, 1675-1677. [CrossRef]

8. Norquist, B.M.; Harrell, M.I.; Brady, M.F.; Walsh, T.; Lee, M.K.; Gulsuner, S.; Bernards, S.S.; Casadei, S.; Yi, Q.; Burger, R.A.; et al. Inherited Mutations in Women With Ovarian Carcinoma. JAMA Oncol. 2016, 2, 482-490. [CrossRef]

9. Loveday, C.; Turnbull, C.; Ruark, E.; Xicola, R.M.; Ramsay, E.; Hughes, D.; Warren-Perry, M.; Snape, K.; Breast Cancer Susceptibility, C.; Eccles, D.; et al. Germline RAD51C mutations confer susceptibility to ovarian cancer. Nat. Genet. 2012, 44, 475-476, author reply 476. [CrossRef]

10. Loveday, C.; Turnbull, C.; Ramsay, E.; Hughes, D.; Ruark, E.; Frankum, J.R.; Bowden, G.; Kalmyrzaev, B.; Warren-Perry, M.; Snape, K.; et al. Germline mutations in RAD51D confer susceptibility to ovarian cancer. Nat. Genet. 2011, 43, 879-882. [CrossRef]

11. Watson, P.; Butzow, R.; Lynch, H.T.; Mecklin, J.P.; Jarvinen, H.J.; Vasen, H.F.; Madlensky, L.; Fidalgo, P.; Bernstein, I.; International Collaborative Group on, H. The clinical features of ovarian cancer in hereditary nonpolyposis colorectal cancer. Gynecol. Oncol. 2001, 82, 223-228. [CrossRef]

12. Ramus, S.J.; Song, H.; Dicks, E.; Tyrer, J.P.; Rosenthal, A.N.; Intermaggio, M.P.; Fraser, L.; Gentry-Maharaj, A.; Hayward, J.; Philpott, S.; et al. Germline Mutations in the BRIP1, BARD1, PALB2, and NBN Genes in Women With Ovarian Cancer. J. Natl. Cancer Inst. 2015, 107. [CrossRef] [PubMed]

13. Banno, K.; Kisu, I.; Yanokura, M.; Masuda, K.; Ueki, A.; Kobayashi, Y.; Hirasawa, A.; Aoki, D. Hereditary gynecological tumors associated with Peutz-Jeghers syndrome (Review). Oncol. Lett. 2013, 6, 1184-1188. [CrossRef] [PubMed]

14. Lilyquist, J.; LaDuca, H.; Polley, E.; Davis, B.T.; Shimelis, H.; Hu, C.; Hart, S.N.; Dolinsky, J.S.; Couch, F.J.; Goldgar, D.E. Frequency of mutations in a large series of clinically ascertained ovarian cancer cases tested on multi-gene panels compared to reference controls. Gynecol. Oncol. 2017, 147, 375-380. [CrossRef] [PubMed]

15. Carter, N.J.; Marshall, M.L.; Susswein, L.R.; Zorn, K.K.; Hiraki, S.; Arvai, K.J.; Torene, R.I.; McGill, A.K.; Yackowski, L.; Murphy, P.D.; et al. Germline pathogenic variants identified in women with ovarian tumors. Gynecol. Oncol. 2018, 151, 481-488. [CrossRef] 
16. Schubert, S.; van Luttikhuizen, J.L.; Auber, B.; Schmidt, G.; Hofmann, W.; Penkert, J.; Davenport, C.F.; Hille-Betz, U.; Wendeburg, L.; Bublitz, J.; et al. The identification of pathogenic variants in BRCA1/2 negative, high risk, hereditary breast and/or ovarian cancer patients: High frequency of FANCM pathogenic variants. Int. J. Cancer 2019, 144, 2683-2694. [CrossRef]

17. Daly, M.B.; Pilarski, R.; Berry, M.; Buys, S.S.; Farmer, M.; Friedman, S.; Garber, J.E.; Kauff, N.D.; Khan, S.; Klein, C.; et al. NCCN Guidelines Insights: Genetic/Familial High-Risk Assessment: Breast and Ovarian, Version 2.2017. J. Natl. Compr. Cancer Netw. JNCCN 2017, 15, 9-20. [CrossRef]

18. Domchek, S.M.; Friebel, T.M.; Neuhausen, S.L.; Wagner, T.; Evans, G.; Isaacs, C.; Garber, J.E.; Daly, M.B.; Eeles, R.; Matloff, E.; et al. Mortality after bilateral salpingo-oophorectomy in BRCA1 and BRCA2 mutation carriers: A prospective cohort study. Lancet. Oncol. 2006, 7, 223-229. [CrossRef]

19. Soukupova, J.; Zemankova, P.; Lhotova, K.; Janatova, M.; Borecka, M.; Stolarova, L.; Lhota, F.; Foretova, L.; Machackova, E.; Stranecky, V.; et al. Validation of CZECANCA (CZEch CAncer paNel for Clinical Application) for targeted NGS-based analysis of hereditary cancer syndromes. PLoS ONE 2018, 13, e0195761. [CrossRef]

20. King, M.C.; Marks, J.H.; Mandell, J.B.; New York Breast Cancer Study, G. Breast and ovarian cancer risks due to inherited mutations in BRCA1 and BRCA2. Science 2003, 302, 643-646. [CrossRef]

21. Rafnar, T.; Gudbjartsson, D.F.; Sulem, P.; Jonasdottir, A.; Sigurdsson, A.; Jonasdottir, A.; Besenbacher, S.; Lundin, P.; Stacey, S.N.; Gudmundsson, J.; et al. Mutations in BRIP1 confer high risk of ovarian cancer. Nat. Genet. 2011, 43, 1104-1107. [CrossRef] [PubMed]

22. Bonache, S.; Esteban, I.; Moles-Fernandez, A.; Tenes, A.; Duran-Lozano, L.; Montalban, G.; Bach, V.; Carrasco, E.; Gadea, N.; Lopez-Fernandez, A.; et al. Multigene panel testing beyond BRCA1/2 in breast/ovarian cancer Spanish families and clinical actionability of findings. J. Cancer Res. Clin. Oncol. 2018, 144, $2495-2513$. [CrossRef]

23. Lynch, H.T.; de la Chapelle, A. Hereditary colorectal cancer. N. Engl. J. Med. 2003, 348, 919-932. [CrossRef] [PubMed]

24. Lu, H.M.; Li, S.; Black, M.H.; Lee, S.; Hoiness, R.; Wu, S.; Mu, W.; Huether, R.; Chen, J.; Sridhar, S.; et al. Association of Breast and Ovarian Cancers With Predisposition Genes Identified by Large-Scale Sequencing. JAMA Oncol. 2018. [CrossRef] [PubMed]

25. Kurian, A.W.; Ward, K.C.; Howlader, N.; Deapen, D.; Hamilton, A.S.; Mariotto, A.; Miller, D.; Penberthy, L.S.; Katz, S.J. Genetic Testing and Results in a Population-Based Cohort of Breast Cancer Patients and Ovarian Cancer Patients. J. Clin. Oncol. 2019, JCO1801854. [CrossRef]

26. Yang, X.; Leslie, G.; Doroszuk, A.; Schneider, S.; Allen, J.; Decker, B.; Dunning, A.M.; Redman, J.; Scarth, J.; Plaskocinska, I.; et al. Cancer Risks Associated With Germline PALB2 Pathogenic Variants: An International Study of 524 Families. J. Clin. Oncol. 2020, 38, 674-685. [CrossRef] [PubMed]

27. Kleiblova, P.; Stolarova, L.; Krizova, K.; Lhota, F.; Hojny, J.; Zemankova, P.; Havranek, O.; Vocka, M.; Cerna, M.; Lhotova, K.; et al. Identification of deleterious germline CHEK2 mutations and their association with breast and ovarian cancer. Int. J. Cancer 2019. [CrossRef]

28. Harter, P.; Hauke, J.; Heitz, F.; Reuss, A.; Kommoss, S.; Marme, F.; Heimbach, A.; Prieske, K.; Richters, L.; Burges, A.; et al. Prevalence of deleterious germline variants in risk genes including BRCA1/2 in consecutive ovarian cancer patients (AGO-TR-1). PLoS ONE 2017, 12, e0186043. [CrossRef] [PubMed]

29. Whitworth, J.; Skytte, A.B.; Sunde, L.; Lim, D.H.; Arends, M.J.; Happerfield, L.; Frayling, I.M.; van Minkelen, R.; Woodward, E.R.; Tischkowitz, M.D.; et al. Multilocus Inherited Neoplasia Alleles Syndrome: A Case Series and Review. JAMA Oncol. 2016, 2, 373-379. [CrossRef]

30. Stradella, A.; Del Valle, J.; Rofes, P.; Feliubadalo, L.; Grau Garces, E.; Velasco, A.; Gonzalez, S.; Vargas, G.; Izquierdo, A.; Campos, O.; et al. Does multilocus inherited neoplasia alleles syndrome have severe clinical expression? J. Med. Genet. 2018. [CrossRef]

31. Whitworth, J.; Smith, P.S.; Martin, J.E.; West, H.; Luchetti, A.; Rodger, F.; Clark, G.; Carss, K.; Stephens, J.; Stirrups, K.; et al. Comprehensive Cancer-Predisposition Gene Testing in an Adult Multiple Primary Tumor Series Shows a Broad Range of Deleterious Variants and Atypical Tumor Phenotypes. Am. J. Hum. Genet. 2018, 103, 3-18. [CrossRef]

32. Castera, L.; Harter, V.; Muller, E.; Krieger, S.; Goardon, N.; Ricou, A.; Rousselin, A.; Paimparay, G.; Legros, A.; Bruet, O.; et al. Landscape of pathogenic variations in a panel of 34 genes and cancer risk estimation from 5131 HBOC families. Genet. Med. 2018, 20, 1677-1686. [CrossRef] [PubMed] 
33. Morgan, R.D.; Burghel, G.J.; Flaum, N.; Bulman, M.; Clamp, A.R.; Hasan, J.; Mitchell, C.L.; Schlecht, H.; Woodward, E.R.; Lallo, F.I.; et al. Prevalence of germline pathogenic BRCA1/2 variants in sequential epithelial ovarian cancer cases. J. Med. Genet. 2019, 56, 301-307. [CrossRef] [PubMed]

34. Plaskocinska, I.; Shipman, H.; Drummond, J.; Thompson, E.; Buchanan, V.; Newcombe, B.; Hodgkin, C.; Barter, E.; Ridley, P.; Ng, R.; et al. New paradigms for BRCA1/BRCA2 testing in women with ovarian cancer: Results of the Genetic Testing in Epithelial Ovarian Cancer (GTEOC) study. J. Med. Genet. 2016, 53, 655-661. [CrossRef]

35. Rust, K.; Spiliopoulou, P.; Tang, C.Y.; Bell, C.; Stirling, D.; Phang, T.; Davidson, R.; Mackean, M.; Nussey, F.; Glasspool, R.M.; et al. Routine germline BRCA1 and BRCA2 testing in patients with ovarian carcinoma: Analysis of the Scottish real-life experience. BJOG 2018, 125, 1451-1458. [CrossRef] [PubMed]

36. Ruark, E.; Snape, K.; Humburg, P.; Loveday, C.; Bajrami, I.; Brough, R.; Rodrigues, D.N.; Renwick, A.; Seal, S.; Ramsay, E.; et al. Mosaic PPM1D mutations are associated with predisposition to breast and ovarian cancer. Nature 2013, 493, 406-410. [CrossRef] [PubMed]

37. Akbari, M.R.; Lepage, P.; Rosen, B.; McLaughlin, J.; Risch, H.; Minden, M.; Narod, S.A. PPM1D mutations in circulating white blood cells and the risk for ovarian cancer. J. Natl. Cancer Inst. 2014, 106, djt323. [CrossRef]

38. Kleiblova, P.; Shaltiel, I.A.; Benada, J.; Sevcik, J.; Pechackova, S.; Pohlreich, P.; Voest, E.E.; Dundr, P.; Bartek, J.; Kleibl, Z.; et al. Gain-of-function mutations of PPM1D/Wip1 impair the p53-dependent G1 checkpoint. J. Cell Biol. 2013, 201, 511-521. [CrossRef]

39. Pharoah, P.D.P.; Song, H.; Dicks, E.; Intermaggio, M.P.; Harrington, P.; Baynes, C.; Alsop, K.; Australian Ovarian Cancer Study, G.; Bogdanova, N.; Cicek, M.S.; et al. PPM1D Mosaic Truncating Variants in Ovarian Cancer Cases May Be Treatment-Related Somatic Mutations. J. Natl. Cancer Inst. 2016, 108. [CrossRef]

40. Hein, D.W.; Fakis, G.; Boukouvala, S. Functional expression of human arylamine N-acetyltransferase NAT1*10 and NAT1*11 alleles: A mini review. Pharm. Genom. 2018, 28, 238-244. [CrossRef]

41. Butcher, N.J.; Minchin, R.F. Arylamine N-acetyltransferase 1: A novel drug target in cancer development. Pharm. Rev. 2012, 64, 147-165. [CrossRef] [PubMed]

42. Seelinger, M.; Otterlei, M. Helicase-Like Transcription Factor HLTF and E3 Ubiquitin Ligase SHPRH Confer DNA Damage Tolerance through Direct Interactions with Proliferating Cell Nuclear Antigen (PCNA). Int. J. Mol. Sci. 2020, 21, 693. [CrossRef] [PubMed]

43. Nalepa, G.; Clapp, D.W. Fanconi anaemia and cancer: An intricate relationship. Nat. Rev. Cancer 2018, 18, 168-185. [CrossRef] [PubMed]

44. Zhang, L.; Bao, Y.; Riaz, M.; Tiller, J.; Liew, D.; Zhuang, X.; Amor, D.J.; Huq, A.; Petelin, L.; Nelson, M.; et al. Population genomic screening of all young adults in a health-care system: A cost-effectiveness analysis. Genet. Med. 2019. [CrossRef]

45. Best, A.F.; Tucker, M.A.; Frone, M.N.; Greene, M.H.; Peters, J.A.; Katki, H.A. A Pragmatic Testing-Eligibility Framework for Population Mutation Screening: The Example of BRCA1/2. Cancer Epidemiol Biomark. Prev. 2019, 28, 293-302. [CrossRef] [PubMed]

46. Turnbull, C.; Sud, A.; Houlston, R.S. Cancer genetics, precision prevention and a call to action. Nat. Genet. 2018, 50, 1212-1218. [CrossRef]

47. Gabai-Kapara, E.; Lahad, A.; Kaufman, B.; Friedman, E.; Segev, S.; Renbaum, P.; Beeri, R.; Gal, M.; Grinshpun-Cohen, J.; Djemal, K.; et al. Population-based screening for breast and ovarian cancer risk due to BRCA1 and BRCA2. Proc. Natl. Acad. Sci. USA 2014, 111, 14205-14210. [CrossRef]

48. Manchanda, R.; Patel, S.; Gordeev, V.S.; Antoniou, A.C.; Smith, S.; Lee, A.; Hopper, J.L.; MacInnis, R.J.; Turnbull, C.; Ramus, S.J.; et al. Cost-effectiveness of Population-Based BRCA1, BRCA2, RAD51C, RAD51D, BRIP1, PALB2 Mutation Testing in Unselected General Population Women. J. Natl. Cancer Inst. 2018, 110, 714-725. [CrossRef]

49. George, A.; Kaye, S.; Banerjee, S. Delivering widespread BRCA testing and PARP inhibition to patients with ovarian cancer. Nat. Rev. Clin. Oncol. 2017, 14, 284-296. [CrossRef]

50. Ledermann, J.; Harter, P.; Gourley, C.; Friedlander, M.; Vergote, I.; Rustin, G.; Scott, C.L.; Meier, W.; Shapira-Frommer, R.; Safra, T.; et al. Olaparib maintenance therapy in patients with platinum-sensitive relapsed serous ovarian cancer: A preplanned retrospective analysis of outcomes by BRCA status in a randomised phase 2 trial. Lancet. Oncol. 2014, 15, 852-861, Correction in 2015, 16, e158. [CrossRef] 
51. Chandran, E.A.; Kennedy, I. Significant Tumor Response to the Poly (ADP-ribose) Polymerase Inhibitor Olaparib in Heavily Pretreated Patient With Ovarian Carcinosarcoma Harboring a Germline RAD51D Mutation. JCO Precis. Oncol. 2018, 1-4. [CrossRef]

52. Ngoi, N.Y.L.; Tay, D.; Heong, V.; Thian, Y.L.; Ong, P.Y.; Ow, S.G.W.; Jeyasekharan, A.D.; Lim, Y.W.; Lim, S.E.; Lee, S.C.; et al. Reversal of Bowel Obstruction with Platinum-Based Chemotherapy and Olaparib in Recurrent, Short Platinum-Free Interval, RAD51C Germline Mutation-Associated Ovarian Cancer. JCO Precis. Oncol. 2018, 1-8. [CrossRef]

(C) 2020 by the authors. Licensee MDPI, Basel, Switzerland. This article is an open access article distributed under the terms and conditions of the Creative Commons Attribution (CC BY) license (http://creativecommons.org/licenses/by/4.0/). 